
https://doi.org/10.30534/ijeter/2019/09792019

\title{
Mechanical Behaviour of Mortar Made with Washed Bottom Ash as Sand Replacement
}

\author{
Mohd Fakri Muda ${ }^{1}$, Saffuan Wan Ahmad ${ }^{2}$, Fadhluhartini Muftah ${ }^{3}$, Mohd Syahrul Hisyam Mohd Sani ${ }^{*}$ \\ ${ }^{1}$ Faculty of Civil Engineering, Universiti Teknologi Mara Cawangan Pahang, 26400 Bandar Jengka, Pahang, \\ Malaysia, fakri@uitm.edu.my \\ ${ }^{2}$ Faculty of Civil Engineering, Universiti Malaysia Pahang, 26300 Gambang, Kuantan, Pahang, Malaysia, \\ saffuan@ump.edu.my \\ ${ }^{3}$ Faculty of Civil Engineering, Universiti Teknologi Mara Cawangan Pahang, 26400 Bandar Jengka, Pahang, \\ Malaysia, fadhlu@uitm.edu.my \\ ${ }^{4}$ Faculty of Civil Engineering, Universiti Teknologi Mara Cawangan Pahang, 26400 Bandar Jengka, Pahang, \\ Malaysia,msyahrul210@uitm.edu.my
}

\begin{abstract}
Bottom ash (BA) is a waste material which found from the electrical power plant whether collect from a boiler or landfill area. While, mortar is a construction material which incorporated between sand, cement and water. There are a lot of problems such as environmental impact and limited sources of raw material which able to solve by using waste material as a sand replacement in mortar. Thus, BA is selected and treated with fully submerging in the water to recognise as washed BA. The process is used for minimised the carbon content of the BA. Washed BA is utilised in a mortar with $5 \%, 10 \%$, $15 \%, 20 \%$ and $25 \%$ of sand replacement and compared the result with control mix $(0 \%)$ of sand replacement. The mortar design mix proportion is depended on cement to sand ratio of $1: 3$ with 0.55 of water-cement ratio. There are two testings, workability for fresh condition and compressive strength for hardening condition of the mortar is done. As a result, the height of the slump is reduced with increasing of the sand replacement in mortar. Additionally, the maximum load and compressive strength of the mortar is also decreased when the washed BA as a sand replacement added. Lastly, the specimen with $15 \%$ of sand replacement of washed BA is the best mortar mix which provided reasonable compressive strength and workability for further study.
\end{abstract}

Keywords : Mechanical Behaviour, Mortar, Washed Bottom Ash, Sand Replacement

\section{INTRODUCTION}

The section is divided into numerous parts such as bottom ash (BA) in general, waste material in
Malaysia, problem statement, BA in the mortar and other materials as sand replacement in mortar.

\subsection{Bottom Ash}

Bottom ash (BA) is a waste material of coal which collected from the boiler or furnace after being used in the electrical power plant. Sometimes, BA is collected from a boiler or from the landfill area which exposed to wet or dry weather conditions and exposed to impurities. Normally, there is a lot of raw material which utilised as a powerful material to generate electricity such as coal and petrol or by using natural sources such as wind, sun and water. Coal and petrol are a popular way to generate electricity in a fast and easy process without any time limit and not depending on the season. Reference [1] have discussed that coal is a worldwide source of energy with $40 \%$ of generating electricity and started using coal as an energy source in Malaysia since 1988. When coal is used, there is a lot of amount of waste material will produce. In general, there are two forms of waste material which produced from a coal electrical power plant is in BA and fly ash. Reference [2] stated that BA is referred to a fraction which discharged out from the combustion chamber while fly ash is entrained with the flue gas and collected after a process of flue gas cleaning. BA is broadly used in concrete technology as sand or cement replacement and highway engineering as an additive in road pavement production [3].

\subsection{Waste Material in Malaysia}

Waste material in Malaysia is divided into several categories such as solid waste, liquid waste and gas waste. All the waste is organised by evaluating the population and economic status of the country and normally stressed to $3 \mathrm{R}$ approach which promoted to reduce, reuse and recycle the waste material. 
Normally, solid waste consists of construction waste, agriculture waste, industrial waste, clinical waste and household waste. All the sources solid waste can be classified into food waste, plastics, paper, glass and metals. Reference [4] have reported that the waste material is increased eventually from 18,000 tonnes to more than 30,000 tonnes per day by the year 2020 which generated in Peninsular Malaysia. The waste material is carried through the several recycle processes; some are reused back as construction material or other material and some are delivered to landfill area which classified as limited area and produced a lot of environmental problems. The solid waste composition in Malaysia from the study of [5] is represented in Figure 1.

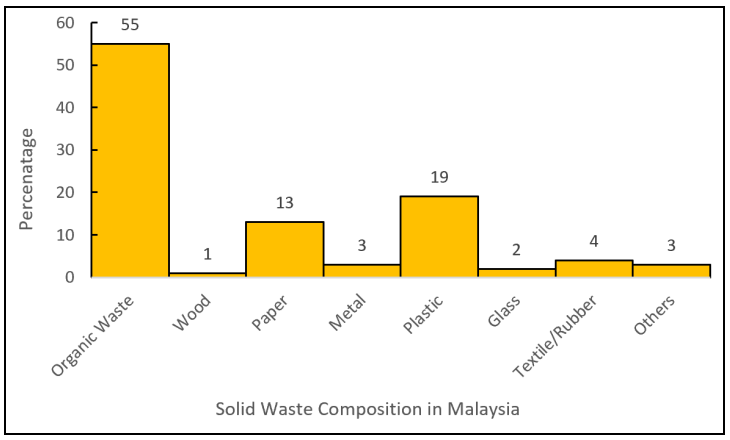

Figure 1: The typical solid waste structure and composition in Malaysia

\subsection{Problem Statement}

Mortar is the construction and building material which mixed between the binder especially cement or other cement replacement with same size and properties of cement, and sand. The mortar is separated into several shapes and types according to their application. The mortar is consisting of cement which the most popular, lime mortar, mud mortar, alkali-activated mortar, self-compacting mortar and geopolymer mortar. Mortar is classified as a special mortar when the natural or traditional material is replaced or added with other material from waste or artificial product, and also according to mortar application. Reference [6] have reported that the polymer is used to solve or reduce the disadvantages of the mortar and some example of the polymers are latex, resins, water-soluble and monomers. The ratio between cement and sand is according to application such as 1:2, 1:3, 1:4 and etc.

Due to a lot of environmental problems and increasing of the human population with parallelly increasing of the construction and infrastructure project, the traditional raw material for producing mortar is becoming limited. Reference [7] have mentioned the sand is becoming shortage and a lot of environmental problems is affected such as water pollution, riverbank erosion, loss of biodiversity, deterioration in water quality and riverbed degradation. Reference [8] have reported that the construction activity is increased, caused the high request of the user for using the best and quality material, and lastly, the mining activity of the material is increasing and creating the unstable of environment.

Besides, the extreme weather such as increasing in heat frequency is the most important issue of energy required in the building. Reference [9] have mentioned that the energy efficiency in the building is not only minimised the electrical energy demand but also focussed on the performance of building especially operational energy and material used in building. Energy efficiency in the also discussed on natural ventilation, carbon dioxide $\left(\mathrm{CO}_{2}\right)$ emission and daylighting, and thermal insulation is very costly therefore choose the appropriate material is more significant [9].

\subsection{Bottom Ash in Mortar}

BA is used broadly as a cement and sand replacement in concrete, mortar or road construction material. There are many studies focussed on cement and sand replacement, currently. Thus, the study in the paper is only concentrated on sand replacement in mortar. Reference [10] have reported that the $\mathrm{BA}$ is contained the reactive fraction with pozzolanic properties and the strength of mortar with the sand replacement of below $40 \%$ of BA is causing the improvement.

Reference [11] studied the compressive and flexural strength of the mortar made with the coal-based pond ash as a sand replacement of $0 \%$ to $100 \%$ which collected from the Bhusawal thermal power plant in India. They concluded that the coal-based pond ash is able to increase in the amount of $\mathrm{CSH}$ gel and strength is more practical when replaced the sand with $40 \%$ in cement mortar. Reference [12] have stated that the BA is a porous material and utilised as a sand replacement in the mortar by volume of $25 \%, 50 \%, 75 \%$ and $100 \%$ for determining their mechanical performance. Reference [13] have studied the BA as a sand replacement in mortar for the percentage of $10 \%$, $20 \%, 30 \%, 40 \%, 50 \%, 75 \%$ and $100 \%$ and evaluated the density, thermal conductivity, water absorption, ultrasonic pulse velocity, microstructure and gas permeability. Reference [14] have studied the behaviour of masonry mortar with BA of $20 \%$, $30 \%, 40 \%$ and $50 \%$ as a sand replacement by weight with mix proportion of 1:4. 
Some research on BA is discussed as a sand replacement in other types of mortar for instance high strength mortar [15], high-performance mortar [16] and geopolymer mortar [17].

\subsection{Other Waste Materials as Sand Replacement in Mortar}

There are many researchers is studying the waste material or product from the natural weathering process as sand in the mortar. Reference [7] have mentioned the laterite from an abundant soil material which through the natural weathering process and used as sand in the mortar after treated and processed. Reference [18] have studied the effect of compressive strength of granulated ferronickel slag which produced from the smelting of nickel ore as a sand replacement with the percentage of $0 \%, 25 \%, 50 \%, 75 \%$ and $100 \%$ in mortar. Reference [19] have assessed the effect of mortar when natural sand is replaced with fine recycled concrete aggregate and revealed the unfavourable effect on the compressive, flexural strength and drying shrinkage in mortar. The mechanical behaviour includes compressive and tensile strength, and adhesive strength is studied when the natural sand in mortar mixes is replaced with the waste granite powder by volume (30-40\%) which collected from cutting and finishing activity of granite block production [20].

Besides, the sand replacement with a range of 0 to $60 \%$ of limestone waste which produced from cutting and polishing activity is mixed in ratio 1:3 and 1:6 in volume and lastly evaluated their strength by [8]. There is a lot of sand replacement which utilised in mortar from waste product such as cathode ray tube glass waste [21], rubber ash [22], waste glass [23], demolished brick masonry [24], crushed rock powder [25], wood ash [26] and copper slag [27].

\subsection{Mechanical Behaviour of the Mortar}

Mechanical behaviour of the mortar is usually influenced by the material that's been used in the mixes and design mix. The mechanical behaviour of the mortar is focalised on strength especially compressive, flexural and tensile, toughness, durability and elastic modulus. In general, the strength behaviour of compressive, flexural and tensile is used the cube, beam and cylinder mould, respectively for gaining the experimental data. The strength is normally obtained after being cured in 3 , $7,28,45,60$ or 90 days. The most important strength data are collected for early age between 3 to 7 days of curing and mature age ( 28 days) of curing. The strength is started to increase quickly at an early age and continued slowly after an early age. The compressive strength of mortar is normally related to the strength of cement which increased or decreased depending on the formation of CSH gel during the hydration which classified as neverending progression.

The main objective of the study is to determine the mechanical behaviour especially compressive strength of the special mortar when incorporating with the BA as sand replacement. Next, the second objective of the study is to determine the workability test of the mortar and check the relationship between workability and compressive strength test.

\section{MATERIAL AND EXPERIMENTAL METHOD}

Materials that used in the mortar production are cement from Portland cement type, natural sand, bottom ash (BA) and tap water. Natural sand is carried for the cleaning process and distributed into the sieving process. BA as shown in Figure 2 (a) is passed through the process of cleaning and removing or minimising the carbon content by using clean water and water tank. The BA is placed in the water tank and allowed sink in water for 1 week for removing the carbon in BA particle. All carbon in the black colour is floating on the water in the tank after 1 week and separated by taking them out from the tank. The BA is now is became light grey colour rather than before in black colour and recognised as washed BA.

The mix proportion of the mortar is a $1: 3$ ratio which represented the cement to sand ratio. The washed BA has replaced the natural sand in the percentage of $5 \%, 10 \%, 15 \%, 20 \%$ and $25 \%$ as illustrated in Figure 2 (b) and (c), respectively. The method of the study is limited to the workability test and the compressive strength test of the mortar. The cube moulds of $100 \mathrm{~mm} \times 100 \mathrm{~mm} \times 100 \mathrm{~mm}$ are used and the curing process is done with fully submerging the specimens in water for 7 and 28 days. Total of specimens are 36 cubes includes control mix (0\% sand replacement) and sand replacement of $5 \%$ to $25 \%$. The water-cement ratio of the mortar mixes is 0.55 . There is no superplasticiser used in the study because to obtain the relationship between the workability and compressive strength.

All mortar ingredients are placed into the drum mixer after being weighted accordingly to mix proportions. Then, all ingredients are mixed together 
in a drum mixer in uniform and fresh mortar is placed into cube mould in several layers with fully compacting in each layer as shown in Figure 3. Other fresh mortar is tested for workability. The workability test of mortar is tested by using the slump test. After 28 days, the cubes are removed from the mould and located in the water tank for the curing process. Lastly, the cube is tested for compressive strength for 7 and 28 days. All data of workability and compressive strength test is recorded. In the beginning, BA and washed BA is attained and tested to document the result of the chemical composition by using X-ray fluorescence (XRF) method. The physical behaviour of BA and washed BA is observed.

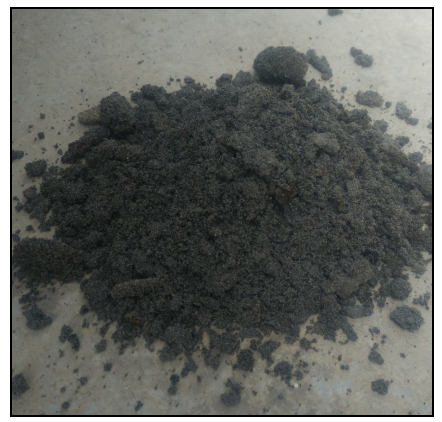

(a)

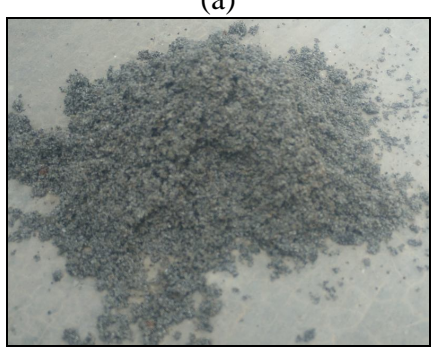

(b)

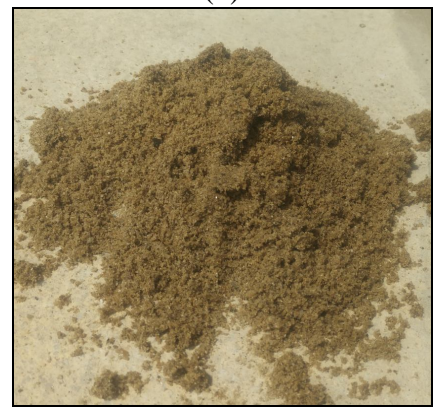

(c)

Figure 2: The photographs of materials (a) bottom ash, (b) washed bottom ash and (c) sand

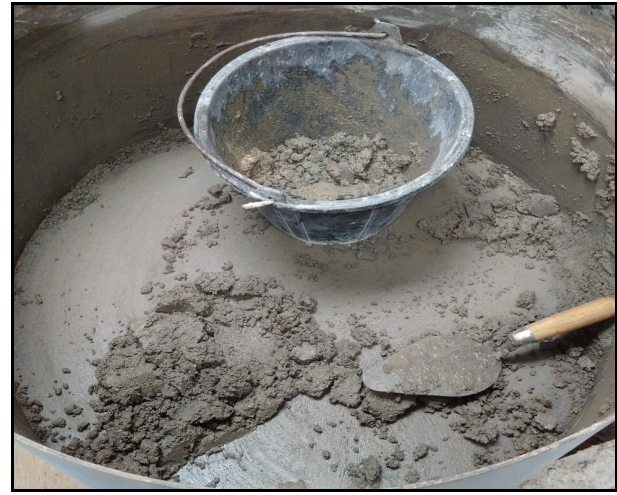

Figure 3: The fresh mortar after being mixed

\section{RESULT AND DISCUSSION}

The result and discussion of the mortar are divided into two parts, workability test and compressive strength of the mortar. However, the result and discussion of the study are started with the chemical composition of BA with washed BA which procured from the treatment process. The colour of the BA, washed BA and sand is recorded that the BA in dark grey colour, washed BA in light grey colour and sand in the usual colour of brown. In observation, $\mathrm{BA}$ and washed BA is smoother when compared with sand which placed in hand.

\subsection{Chemical Composition}

The chemical composition is important to get some information when the treatment process of releasing the Carbon content which effected to the mortar behaviour is done and organised in Table 1. The $\mathrm{SiO}_{2}$ is increased by around $28.10 \%$ when BA is placed in the water through the process of immersing. Although, the composition of $\mathrm{Al}_{2} \mathrm{O}_{3}$, $\mathrm{Fe}_{2} \mathrm{O}_{3}, \quad \mathrm{TiO}_{2}$ and $\mathrm{CaO}$ are decreased by approximately $16.91 \%, 43.4 \%, 12.01 \%$ and $31.48 \%$, respectively. The loss on ignition (LOI) of BA has increased about $74.39 \%$ when reformed to washed BA. The chemical composition of washed BA is compared with previous studies. The washed BA is recorded to have the same amount of $\mathrm{SiO}_{2}$ and $\mathrm{Al}_{2} \mathrm{O}_{3}$ when compared with the study by [28] and [29]. Reference [30] have mentioned about the treated $\mathrm{BA}$ which consists of the major chemical composition of $\mathrm{SiO}_{2}, \mathrm{Al}_{2} \mathrm{O}_{3}$ and $\mathrm{Fe}_{2} \mathrm{O}_{3}$ because the $\mathrm{BA}$ is classified to contain a glass matter, quartz particles, and ferrous and non-ferrous metals. 
Mohd Fakri Muda et al., International Journal of Emerging Trends in Engineering Research, 7(9), September 2019, 268 - 275

Table 1: The result of the chemical composition of bottom ash, washed bottom ash and bottom ash from the previous study.

\begin{tabular}{|c|c|c|c|c|}
\hline Chemical Composition & $\begin{array}{c}\text { Bottom Ash Weight } \\
\text { percent (\%) }\end{array}$ & $\begin{array}{c}\text { Washed Bottom Ash } \\
\text { Weight percent (\%) }\end{array}$ & $\begin{array}{c}\text { Bottom } \\
\text { Ash [28] }\end{array}$ & $\begin{array}{c}\text { Bottom } \\
\text { Ash [29] }\end{array}$ \\
\hline Silicon Dioxide, $\mathrm{SiO}_{2}$ & 39.4 & 54.8 & 58.7 & 52.2 \\
\hline Aluminum Oxide, $\mathrm{Al}_{2} \mathrm{O}_{3}$ & 34.3 & 28.5 & 20.1 & 27.5 \\
\hline Iron Oxide, $\mathrm{Fe}_{2} \mathrm{O}_{3}$ & 15 & 8.49 & 6.2 & 6.0 \\
\hline Titanium Dioxide, $\mathrm{TiO}_{2}$ & 3.08 & 2.71 & - & - \\
\hline Magnesium Oxide, $\mathrm{MgO}$ & 1.57 & 0.35 & 1.6 & 1.7 \\
\hline Calcium Oxide, $\mathrm{CaO}$ & 6.13 & 4.2 & 9.5 & 5.9 \\
\hline Sodium Oxide, $\mathrm{Na}_{2} \mathrm{O}$ & - & 0.08 & 0.1 & - \\
\hline Potassium Oxide, $\mathrm{K}_{2} \mathrm{O}$ & - & 0.45 & 1.0 & 0.6 \\
\hline $\begin{array}{c}\text { Phosphorus pentoxide, } \\
\mathrm{P}_{2} \mathrm{O}_{5}\end{array}$ & - & 0.28 & - & 0.74 \\
\hline $\begin{array}{c}\text { Loss of Ignition }(\mathrm{LOI}) \text { at } \\
1000^{\circ} \mathrm{C}\end{array}$ & 0.63 & 2.46 & 0.8 & 1.8 \\
\hline
\end{tabular}

\subsection{Workability Test - Slump}

The result of the slump test of the fresh mortar is tabulated in Table 2. The height of slump is decreased with increasing of the sand replacement. The highest values of the height of the slump are $5 \%$ specimen and the lowest values of the height of the slump are $25 \%$ specimen among of the sand replacement specimen. The percentage difference between these two specimens is $76.04 \%$ which classified a very high value which parallels with the high of water absorption. The reduction of percentage between control mix with $5 \%, 10 \%$, $15 \%, 20 \%$ and $25 \%$ is $9.43 \%, 23.58 \%, 38.68 \%$, $59.43 \%$ and $78.30 \%$, respectively. The relationship between the height of the slump and the percentage of sand replacement is illustrated in Figure 4. Reference [31] have reported that the workability of concrete by using a compacting factor test is decreased when the BA as sand replacement. This is because the fineness of BA is high when compared with sand and the specific surface of BA is large so need a lot of water in mixing [31]. The statement of water absorption increased with an increasing BA in mortar is correspondingly proven by [32] which analysed the water absorption of mortar at 28 days for $50 \%$ and $100 \%$ sand replacement is $13.28 \%$ and $20.94 \%$, respectively.

Table 2: The slump test result of the mortar

\begin{tabular}{|c|c|c|}
\hline No. & Specimen & $\begin{array}{c}\text { Height of } \\
\text { slump (mm) }\end{array}$ \\
\hline 1 & $\begin{array}{c}\text { Control } \\
(0 \%)\end{array}$ & 106 \\
\hline 2 & $5 \%$ & 96 \\
\hline 3 & $10 \%$ & 81 \\
\hline 4 & $15 \%$ & 65 \\
\hline 5 & $20 \%$ & 43 \\
\hline 6 & $25 \%$ & 23 \\
\hline
\end{tabular}

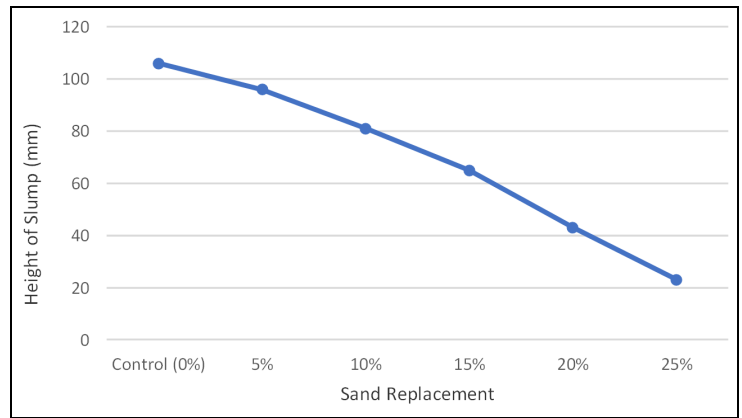

Figure 4: The relationship between the sand replacement (\%) with the height of slump

\subsection{Compressive Strength Test}

The result of the compressive strength of the mortar is tabulated in Table 3 and Figure 5. The maximum load and compressive strength of the mortar are increased when the washed BA as a sand replacement increased from $5 \%$ to $15 \%$. Nevertheless, when the mortar mix incorporated with washed BA more than $15 \%$ the maximum load and compressive strength are reduced. This is because mortar with more than $15 \%$ of washed BA consists of the largest of air void due to high circumstances of water absorption in BA. The early compressive strength of the $15 \%$ of washed BA is shown the highest of maximum load and compressive strength when compared with control mix and reported increase approximately $16.04 \%$. The control mix specimen with $0 \%$ of sand replacement is noted to have a percentage difference of $31.64 \%$ when compared between 7 days and 28 days of curing. Whereas, the percentage difference between 7 days and 28 days of curing for $5 \%, 10 \%, 15 \%, 20 \%$ and $25 \%$ sand replacement are $38.87 \%, 34.94 \%, 15.14 \%$, $12.51 \%$ and $28.96 \%$, respectively. The percentage difference of the control mix specimen with specimen of $5 \%, 10 \%, 15 \%, 20 \%$ and $25 \%$ sand replacement for 28 days are $13.69 \%, 11.54 \%, 4.06 \%, 12.71 \%$ and $23.37 \%$. The relationship of the percentage of sand replacement with compressive strength is illustrated in Figure 6. 
Mohammad Aslam et al., International Journal of Emerging Trends in Engineering Research, 7(9), September 2019, 268 - 275

Table 3: The result of the compressive strength of the mortar

\begin{tabular}{|c|c|c|c|c|}
\hline \multirow{2}{*}{ Specimen } & \multicolumn{2}{|c|}{$\mathbf{7}$ days } & \multicolumn{2}{c|}{$\mathbf{2 8}$ days } \\
\cline { 2 - 5 } & $\begin{array}{c}\text { Maximum } \\
\text { Load (kN) }\end{array}$ & $\begin{array}{c}\text { Compressive } \\
\text { Strength }(\mathbf{M P a})\end{array}$ & $\begin{array}{c}\text { Maximum Load } \\
(\mathbf{k N})\end{array}$ & $\begin{array}{c}\text { Compressive } \\
\text { Strength (MPa) }\end{array}$ \\
\hline Control (0\%) & 139.8 & 13.98 & 204.5 & 20.45 \\
\hline $5 \%$ & 107.9 & 10.79 & 176.5 & 17.65 \\
\hline $10 \%$ & 117.7 & 11.77 & 180.9 & 18.09 \\
\hline $15 \%$ & 166.5 & 16.65 & 196.2 & 19.62 \\
\hline $20 \%$ & 126.8 & 12.68 & 178.5 & 17.85 \\
\hline $25 \%$ & 137.1 & 13.71 & 156.7 & 15.67 \\
\hline
\end{tabular}

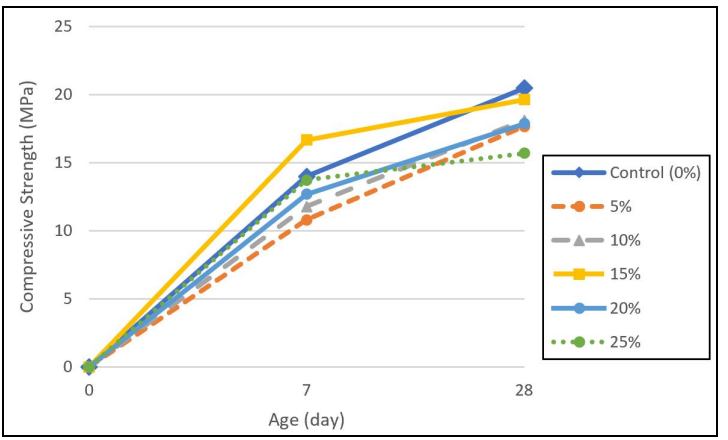

Figure 5: The result of the mortar with a different percentage of sand replacement

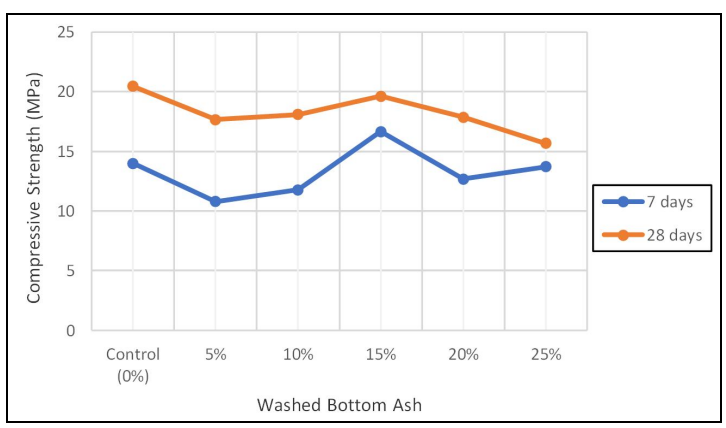

Figure 6: The relationship between the compressive strength and the percentage of washed bottom ash

\subsection{Relationship between Workability and Compressive Strength}

The relationship between workability and compressive strength of the mortar with the different percentage of the sand replacement is analysed and shown in Figure 7 . The relationship between both factors is represented in the ratio of the height of slump to compressive strength of mortar on 7 days and 28 days. The figure shown is the same graph line pattern for 7 days and 28 days. The highest value of ratio for 7 days and 28 days of curing is 8.90 and 5.44, respectively which added $5 \%$ of washed BA. Whilst as, the lowest value of ratio for 7 days and 28 days of curing is noted to have 1.68 and 1.47 , respectively. The ratio of the height of slump to compressive strength is increased when added of 5\% sand replacement by using washed BA. The ratio is illustrated decreased when the sand replacement is increased from $10 \%$ to $25 \%$. The compressive strength of the mortar is becoming low due to the low of workability from the slump test.

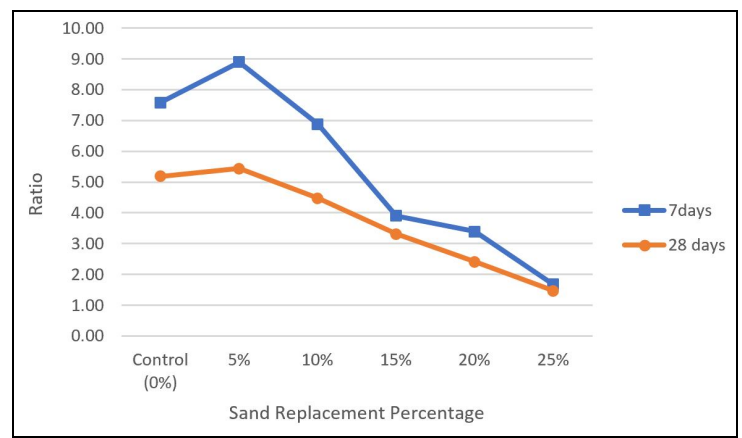

Figure 7: The relationship graph of mortar with different percentage of sand replacement

\section{CONCLUSION}

A study of the mechanical behaviour of washed BA as a sand replacement in mortar has been carried out and analysed completely. The results are compared with the previous study data and the acquirement of the result is drawn as the following conclusion:

- From the experiment, the height of the slump of fresh mortar is decreased when the washed $\mathrm{BA}$ is added. This is because the washed BA is very high of water absorption. For further study, the superplasticiser will be used for solving the water absorption of the mix. 
- $\quad$ From the compressive strength test, the value is decreased with increasing the percentage of washed BA in mortar. The best percentage of sand replacement with a reasonable value of compressive strength on early and mature age is $15 \%$. However, when the superplasticiser is used in mortar mix probability of the compressive strength to be gain is high.

\section{ACKNOWLEDGEMENTS}

The authors gratefully acknowledge the support from Universiti Teknologi Mara (UiTM) Cawangan Pahang and Universiti Malaysia Pahang (UMP). Thanks are also extended to Faculty of Civil Engineering of UiTM Pahang, Kampus Jengka and Faculty of Civil Engineering of UMP for providing laboratory equipment.

\section{REFERENCES}

1. A. Marto, and C. S. Tan. Properties of coal bottom ash from power plants in Malaysia and its suitability as geotechnical engineering material, Jurnal Teknologi, Vol. 78, No. 8-5, pp. 1-10, 2016. https://doi.org/10.11113/jt.v78.9603

2. L. Tosti, A. van Zomeren, J. R. Pels, J.J. Dijkstra, and R. N. J. Comans. Assessment of biomass ash applications in soil and cement mortars, Chemosphere, Vol. 223, pp. 425437, 2019.

https://doi.org/10.1016/j.chemosphere.2019.02.045

3. E. A. Igwe. Comparative study on the effect of some non bituminous modifiers on HMA concrete stiffness modulus: study on optimal performance for heavy traffic, International Journal of Emerging Trends in Engineering Research, Vol. 3, No. 9, pp. 77-85, 2015.

4. I. A. Jereme, C. Siwar, R. A. Begum, B. Abdul Talib, and M. M. Alam. Assessing problems and prospects of solid waste management in Malaysia, Journal of Social Sciences and Humanities, Vol. 10, No. 2, pp. 70-87, 2015.

5. S. H. Fauziah, and P. Agamuthu. Recycling of household organic waste in Malaysia: the challenges, in Proc. International Symposium of Environmental Science and Technology, Shanghai, China, 2009, pp. 2234-2240.

6. D. N. Gomez-Balbuena, T. Lopez-Lara, J. B. Hernandez-Zaragoza, R. G. Ortiz-Mena, M. G. Navarro-Rojero, J. Horta-Rangel, R. SalgadoDelgado, V. M. Castano, and E. RojasGonzalez. Polymer-Cement Mortar with Quarry Waste as Sand Replacement,
Advances in Materials Science and Engineering, pp. 1-10, 2018. https://doi.org/10.1155/2018/3984835

7. S. C. Yaragal, S. N. Basavana Gowda, and C. Rajasekaran. Characterization and performance of processed lateritic fine aggregates in cement mortars and concretes, Construction and Building Materials. Vol. 200, pp. 10-25, 2019.

https://doi.org/10.1016/j.conbuildmat.2018.12.072

8. H. S. Chouhan, P. Kalla, R. Nagar, and P. K. Gautam. Gainful utilization of dimensional limestone waste as fine aggregate in cement mortar mixes, Construction and Building Materials, Vol. 221, pp. 363-374, 2019.

9. A. Ghosh, A. Ghosh, and S. Neogi. Reuse of fly ash and bottom ash in mortars with improved thermal conductivity performance for buildings, Heliyon, Vol. 4, pp. 1-32, 2018.

10. S. S. G. Hashemi, H. Mahmud, J. N. Y. Djobo, C. G. Tan, B. C. Ang, and N. Ranjbar. Microstructural characterization and mechanical properties of bottom ash mortar, Journal of Cleaner Production, Vol. 170, pp. 797-804, 2018.

https://doi.org/10.1016/j.jclepro.2017.09.191

11. D. Lal, A. Chatterjee, and A. Dwivedi. Investigation of properties of cement mortar incorporating pond ash - an environmental sustainable material, Construction and Building Materials, Vol. 209, pp. 20-31, 2019.

12. V. Caprai, A. Lazaro, and H. J. H. Brouwers. Waterglass impregnation of municipal solid waste incineration bottom ash applied as sand replacement in mortars. Waste Management, Vol. 86, pp. 87-96, 2019.

13. E. Baite, A. Messan, K. Hannawi, F. Tsobnang, and W. Prince. Physical and transfer properties of mortar containing coal bottom ash aggregates from Tefereyre (Niger), Construction and Building Materials, Vol. 125, pp. 919-926, 2016.

14. P. Ramadoss, and T. Sundararajan. Utilization of Lignite-based Bottom Ash as Partial Replacement of fine aggregate in masonry mortar, Arabian Journal for Science and Engineering, Vol. 39, No. 2, pp. 737-745, 2014. https://doi.org/10.1007/s13369-013-0703-1

15. H. K. Kim, K. A. Ha, and H. K. Lee. Internalcuring efficiency of cold-bonded coal bottom ash aggregate for high-strength mortar, Construction and Building Materials, Vol. 126, pp. 1-8, 2016. 
16. M. Wyrzykowski, S. Ghourchian, S. Sinthupinyo, N. Chitvoranund, T. Chintana, and P. Lura. Internal curing of high performance mortars with bottom ash, Cement and Concrete Composites, Vol. 71, pp. $1-9,2016$.

17. D. Hardjito, and S. S. Fung. Parametric study on the properties of geopolymer mortar incorporating bottom ash, Concrete Research Letters, Vol. 1, No. 3, pp. 115-124, 2010.

18. A. K. Saha, and P. K. Sarker. Compressive strength of mortar containing ferronickel slag as replacement of natural sand, Procedia Engineering, Vol. 171, pp. 689-694, 2017.

19. L. Li, B. J. Zhan, J. Lu, and C. S. Poon. Systematic evaluation of the effect of replacing river sand by different particle size ranges of fine recycled concrete aggregates (FRCA) in cement mortars, Construction and Building Materials, Vol. 209, pp. 147-155, 2019.

20. L. K. Gupta, and A. K. Vyas. Impact on mechanical properties of cement sand mortar containing waste granite powder, Construction and Building Materials, Vol. 191, pp. 155-164, 2018.

21. H. Zhao, and C. S. Poon. A comparative study on the properties of the mortar with the cathode ray tube funnel glass sand at different treatment methods, Construction and Building Materials, Vol. 148, pp. 900-909, 2017.

22. M. S. Senin, S. Shahidan, A. S. Leman, and N. I. R. Ramzi Hannan. Properties of cement mortar containing rubber ash as sand replacement, IOP Conference Series: Materials Science and Engineering, Vol. 160, pp. 012055 - 1-9, 2016.

23. N. Degirmenci, A. Yilmaz, and O. A. Cakir. Utilization of waste glass as sand replacement in cement mortar, Indian Journal of Engineering \& Materials Sciences, Vol. 18, pp. 303-308, 2011.

24. P. Srujhana, R. J. Menon, S. M. Basutkar, and M. V. Renuka Devi. Demolished brick masonry as a replacement of river sand in cement and cement lime mortar, AIP Conference Proceedings, Vol. 2039, No. 1, pp. 020049, 2018. https://doi.org/10.1063/1.5079008

25. Nagabhushana and H. Sharada Bai. Use of crushed rock powder as replacement of fine aggregate in mortar and concrete, Indian
Journal of Science and Technology, Vol. 4, No. 8, pp. 917-922, 2011.

26. L. M. Ottosen, E. O. Hansen, P. E. Jensen, G. M. Kirkelund, and P. Goltermann. Wood ash used as partly sand and/or cement replacement in mortar, International Journal of Sustainable Development and Planning, Vol. 11, No. 5, pp. 781-791, 2016. https://doi.org/10.2495/SDP-V11-N5-781-791

27. K. B. P. Reddy, K. Tanuja, and N. V. D. Naidu. Use of copper slag in concrete and cement mortars as replacement of sand, International Research Journal of Engineering and Technology, Vol. 3, No. 9, pp. 254-260, 2016.

28. S. Oruji, N. A. Brake, L. Nalluri, and R. K. Guduru. Strength activity and microstructure of blended ultra-fine coal bottom ash-cement mortar, Construction and Building Materials, Vol. 153, pp. 317-326, 2017.

29. C. Argiz, M. A. Sanjuan, and E. Menendez. Coal bottom ash for Portland cement production, Advances in Materials Science and Engineering, pp. 1-7, 2017.

https://doi.org/10.1155/2017/6068286

30. P. Tang, M. V. A. Florea, P. Spiesz, and H. J. H. Brouwers (2014). The application of treated bottom ash in mortar as cement replacement, in Proc. EurAsia Waste Management Symposium, Istanbul, Turkey, 2014, pp. 1077-1082.

31. P. Aggarwal, Y. Aggarwal, and S. M. Gupta. Effect of bottom ash as replacement of fine aggregates in concrete, Asian Journal of Civil Engineering (Building and Housing), Vol. 8, No. 1, pp. 49-62, 2007.

32. E. Baite, A. Messan, K. Hannawi, F. Tsobnang, and W. Prince. Physical and transfer properties of mortar containing coal bottom ash aggregates from Tefereyre (Niger), Construction and Building Materials, Vol. 125, pp. 919-926, 2016. 